\title{
Role of calcium in morphine dependence and naloxone-precipitated withdrawal in mice
}

\author{
This article was published in the following Dove Press journal: \\ Journal of Experimental Pharmacology \\ 18 February 2011 \\ Number of times this article has been viewed
}

\author{
Vikas Seth \\ Prerna Upadhyaya \\ Vijay Moghe \\ Mushtaq Ahmad \\ Department of Pharmacology, \\ Mahatma Gandhi Medical College, \\ Jaipur, Rajasthan, India
}

Correspondence: Vikas Seth

Department of Pharmacology, Mahatma Gandhi Medical College, Sitapura, Jaipur 302022, India

Tel +9l 9983336746

Fax +9| |4| 277 |359

Email drvseth@rediffmail.com
Purpose: To explore the role of calcium in morphine withdrawal syndrome using various agents affecting calcium levels in cytoplasm.

Methods: Mice were rendered dependent on morphine by subcutaneous injection of morphine, and withdrawal was induced 4 hours later by injecting the opioid antagonist, naloxone. Mice were observed for 30 minutes for signs of withdrawal, ie, characteristic jumping, hyperactivity, urination, and diarrhea. Various calcium channel blockers were injected intraperitoneally 30 minutes before naloxone to evaluate their influence on the severity of the withdrawal syndrome. We also tested the effect of combination levodopa-carbidopa pretreatment and its interaction with a selective alpha-1 blocker, terazosin, on naloxone-precipitated withdrawal in mice acutely dependent on morphine.

Results: A significant dose-dependent attenuation of naloxone-induced morphine withdrawal syndrome was observed with calcium channel blockers, ie, verapamil $20 \mathrm{mg} / \mathrm{kg}(P<0.05)$ and diltiazem $30 \mathrm{mg} / \mathrm{kg}(P<0.01)$. Combination levodopa-carbidopa pretreatment facilitated the morphine withdrawal syndrome, and this was found to be blocked by terazosin, although not to a statistically significant $(P>0.05)$ extent.

Conclusion: The results indicate that calcium plays an important role in the genesis of morphine dependence and withdrawal, and suggest the usefulness of calcium channel blockers in the management of morphine withdrawal syndrome.

Keywords: calcium channel blockers, opioid abstinence, verapamil, diltiazem, nifedipine, levodopa-carbidopa combination

\section{Introduction}

Opioids are the most effective drugs for the management of pain, but are associated with the problem of dependence and tolerance, which limits their clinical use. ${ }^{1,2}$ Extensive research is continuing to achieve a better understanding of the biologic mechanisms that underlie these phenomena, which will help in the identification of pharmacological treatments for opioid withdrawal syndrome. ${ }^{3,4}$ Of the various mechanisms studied after morphine treatment, voltage-dependent calcium channels have provided the most promising breakthrough. ${ }^{5}$ In the last decade, there has been a vast expansion in the knowledge of the role played by calcium channel blockers in the central nervous system. Calcium channel blockers have also been investigated for the management of drug abuse. ${ }^{6}$

It has been shown that modifications in $\mathrm{Ca}^{2+}$ fluxes seem to play a basic role, not only in the acute effects of morphine, but also in the manifestations of morphine withdrawal syndrome. ${ }^{7,8}$ Studies have shown that there is an increase in the number of dihydropyridine-sensitive binding sites in the brains of morphine-tolerant mice. ${ }^{9}$ 
Calcium levels in the brain are different between acute and chronic morphine dependence. In acute morphine dependence, there is a fall in the synaptosomal content of $\mathrm{Ca}^{2+},{ }^{10}$ while chronic morphine treatment increases $\mathrm{Ca}^{2+}$ levels in the brain by $100 \% .{ }^{11}$ These increased levels rapidly fall towards normal values during withdrawal. ${ }^{11}$ This suggests that different calcium-related mechanisms are involved in both types of dependence.

The present study explored further the role of calcium and calcium channels in the morphine withdrawal syndrome. On naloxone-precipitated withdrawal in mice acutely dependent on morphine, we evaluated the effect of an L-type agent from each of the three groups of calcium channel blockers, ie, verapamil from the phenylalkylamine group, nifedipine from the dihydropyridine group, and diltiazem from the benzothiazepine group. We also investigated the effect of combination levodopa-carbidopa pretreatment and its interaction with terazosin.

\section{Material and methods}

\section{Animals}

Adult male albino Swiss mice weighing 20-25 g were housed at a controlled room temperature $\left(22-25^{\circ} \mathrm{C}\right)$ under a standard light/dark cycle with free access to food and water. All the animals were acclimatized to the laboratory conditions for at least two days prior to the initiation of any experiment. The experiments were performed between 9 am and 5 pm. Each animal was used for only one experiment, and there were five animals in each group.

\section{Drugs}

Morphine sulfate was obtained from the official agencies of the government of India. All other drugs were supplied by Sigma (Bangalore, India). The drugs were dissolved in normal saline $(0.9 \%)$.

\section{Experimental procedure}

The experiments were conducted after approval from the institutional animal ethics committee of the college. Mice were rendered dependent on morphine by subcutaneous injection of morphine sulfate, and withdrawal was induced four hours later by subcutaneous administration of the opioid antagonist, naloxone, as per the method of Yano and Takemori ${ }^{12}$ and Abdelhamid et al. ${ }^{13}$ Morphine-treated mice, immediately after subcutaneous injection of naloxone, were individually placed in a Plexiglas box $(45 \times 30 \times 30 \mathrm{~cm})$. Animals were observed for vertical jumps, hyperactivity, urination, and diarrhea for a period of 30 minutes. A positive jumping response (where a mouse jumped more than four times during the observation period) ${ }^{12}$ was assigned a score of 4 , hyperactivity response a score of 3 , diarrhea a score of 2 , and urination a score 1.

In the first series of experiments, morphine $125 \mathrm{mg} / \mathrm{kg}$ followed four hours later by naloxone $10 \mathrm{mg} / \mathrm{kg}$ produced a full-blown withdrawal syndrome (jumping positive) in $80 \%-$ $100 \%$ of the animals, with a median withdrawal score of 10 . Twenty minutes before naloxone, normal saline (control group) or calcium channel blockers, ie, verapamil, diltiazem, or nifedipine, was administered at different doses intraperitoneally to observe their influence on withdrawal.

In the second series of experiments, morphine $100 \mathrm{mg} / \mathrm{kg}$ followed by naloxone $2 \mathrm{mg} / \mathrm{kg}$ was used, which induced a full-blown withdrawal syndrome in $20 \%$ of the animals, with a median withdrawal score of 3 . Prior treatment with a levodopa-carbidopa combination was given for two days to observe its influence on morphine withdrawal. In addition, we also wanted to test for any interaction between the levodopa-carbidopa combination and terazosin on withdrawal. For this purpose, 15 minutes before naloxone, saline (control group) or terazosin was administered intraperitoneally to the morphine-naïve mice treated with levodopacarbidopa.

\section{Statistical analysis}

Median withdrawal scores were calculated for each group of five mice in the study. The statistical significance of the difference between the withdrawal scores of the two groups was calculated by nonparametric statistical analysis using the Mann-Whitney $U$ test. ${ }^{14}$ The difference between values was considered significant when $P$ was below 0.05 .

\section{Results}

In the first series of experiments, we investigated the effect of the calcium channel blockers, ie, verapamil, nifedipine, and diltiazem, on naloxone-precipitated morphine withdrawal syndrome. In the second series of experiments, we investigated the influence of combination levodopacarbidopa pretreatment and its interaction with terazosin on naloxone-precipitated morphine withdrawal.

\section{Effect of calcium channel blockers on naloxone-induced withdrawal}

Normal saline (control group) or calcium channel blockers, ie, verapamil, diltiazem, and nifedipine, were administered 
intraperitoneally in different doses 20 minutes before subcutaneous naloxone $10 \mathrm{mg} / \mathrm{kg}$ to the mice treated with subcutaneous morphine $125 \mathrm{mg} / \mathrm{kg}$. In the control group, $80 \%$ of the animals exhibited jumping, and all the animals exhibited hyperactivity, diarrhea, and urination, and the median withdrawal score was 10 .

Verapamil $10 \mathrm{mg} / \mathrm{kg}$ inhibited naloxone-induced withdrawal signs, with stereotypical jumping observed in $20 \%$, hyperactivity in $60 \%$, and diarrhea and urination in $80 \%$, and $20 \%$ of the animals did not show any signs of withdrawal. The median score was $6(P>0.05)$. Verapamil $20 \mathrm{mg} / \mathrm{kg}$ further inhibited the withdrawal syndrome. The signs comprised stereotypical jumping in $10 \%$, hyperactivity in $20 \%$, diarrhea in $60 \%$, and urination in $90 \%$, and $10 \%$ of the animals did not show any sign of withdrawal. The median score in this group was $3(P<0.05$; Figure 1$)$.

Diltiazem $15 \mathrm{mg} / \mathrm{kg}$ inhibited naloxone-induced withdrawal signs, with stereotypical jumping observed in $50 \%$, hyperactivity in $60 \%$, and diarrhea and urination in $80 \%$ of the animals, and $20 \%$ of the animals did not show any withdrawal sign. The median score was $8(P>0.05)$.

Diltiazem $30 \mathrm{mg} / \mathrm{kg}$ further inhibited the withdrawal; none of the animals exhibited stereotypical jumping, hyperactivity was observed in $30 \%$, and diarrhea and urination in $70 \%$. Thirty percent of the animals did not show any signs of withdrawal. The median score was $3(P<0.01$, Figure 2).

Nifedipine $10 \mathrm{mg} / \mathrm{kg}$ inhibited naloxone-induced withdrawal signs, with stereotypical jumping observed in $70 \%$, hyperactivity in $80 \%$, diarrhea in $80 \%$, and urination in $90 \%$ of the animals. Ten percent of the animals did not show any signs of withdrawal. The median score was $10(P>0.05)$. Nifedipine $20 \mathrm{mg} / \mathrm{kg}$ also inhibited the withdrawal syndrome. The signs comprised stereotypical jumping in 30\%, hyperactivity in $70 \%$, and diarrhea and urination in $90 \%$ of the animals. Ten percent of the animals did not show any signs

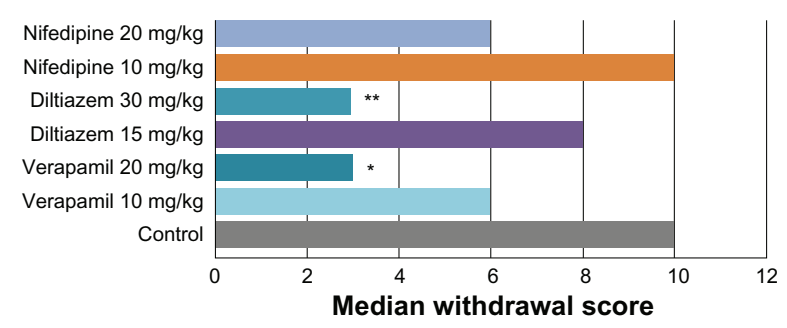

Figure I Effects of calcium channel blockers, ie, verapamil 10 and $20 \mathrm{mg} / \mathrm{kg}$, diltiazem 15 and $30 \mathrm{mg} / \mathrm{kg}$, and nifedipine 10 and $20 \mathrm{mg} / \mathrm{kg}$ on withdrawal precipitated by naloxone $10 \mathrm{mg} / \mathrm{kg}$.

Notes: $* P<0.05 ; * * P<0.01$ versus control.

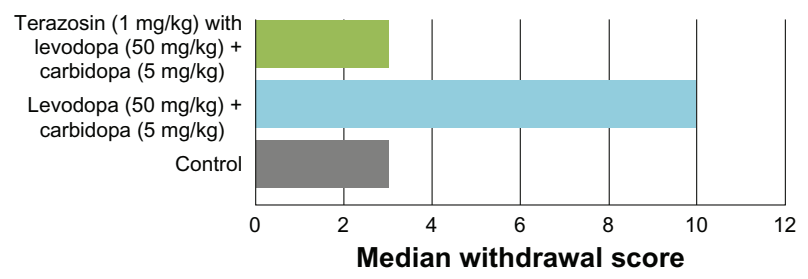

Figure 2 Effect of a combination of levodopa $50 \mathrm{mg} / \mathrm{kg}$ + carbidopa $5 \mathrm{mg} / \mathrm{kg}$ versus terazosin I mg/kg with levodopa $50 \mathrm{mg} / \mathrm{kg}+$ carbidopa $5 \mathrm{mg} / \mathrm{kg}$ on morphine withdrawal precipitated by naloxone $2 \mathrm{mg} / \mathrm{kg}$.

of withdrawal. The median score in this group was 6 $(P>0.05$; Figure 3$)$.

\section{Effect of levodopa-carbidopa pretreatment and its interaction with terazosin on naloxone-induced morphine withdrawal}

The levodopa $50 \mathrm{mg} / \mathrm{kg}$ + carbidopa $5 \mathrm{mg} / \mathrm{kg}$ combination or normal saline (control) was administered subcutaneously for two days. On the third day, subcutaneous morphine $100 \mathrm{mg} / \mathrm{kg}$ was given, followed four hours later by subcutaneous naloxone $2 \mathrm{mg} / \mathrm{kg}$, and withdrawal signs were observed.

In the control group, $20 \%$ of the animals exhibited jumping and hyperactivity, while diarrhea and urination were observed in $70 \%$, and $30 \%$ of the animals did not show any signs of withdrawal. The median withdrawal score was 3 .

In the group treated with levodopa-carbidopa, jumping and hyperactivity were observed in $60 \%$, and diarrhea and urination were observed in all of the animals. The median score in this group was 10 . However, the facilitation produced was not statistically significant $(P>0.05)$ as compared with controls (Figure 4). When terazosin, an alpha-1 antagonist, was given in a dose of $1 \mathrm{mg} / \mathrm{kg}$ subcutaneously 15 minutes prior to naloxone $2 \mathrm{mg} / \mathrm{kg}$ subcutaneously to the mice pretreated with levodopa-carbidopa, inhibition of withdrawal signs was observed. Stereotypical jumping was observed in $20 \%$ and hyperactivity in $40 \%$. All animals showed diarrhea and urination. The median score in this group was 3 $(P>0.05$; Figure 5).

\section{Discussion}

The appearance of a withdrawal syndrome when drug administration is terminated is the only actual evidence of physical dependence. Withdrawal signs and symptoms occur when the drug in a physically-dependent person is abruptly terminated or when an antagonist is administered. Withdrawal symptoms 
tend to be opposite to the original effects of the drug, eg, morphine produces sedation, constipation, and difficulty in micturition, while its withdrawal symptoms include hyperactivity, diarrhea, and urination. Various researchers have used a large dose of morphine, ie, $100 \mathrm{mg} / \mathrm{kg}$ subcutaneously to produce a state of acute dependence where withdrawal is precipitated four hours later by using the antagonist, naloxone. ${ }^{12,13}$ However, in our study, morphine $125 \mathrm{mg} / \mathrm{kg}$ followed four hours later by naloxone $10 \mathrm{mg} / \mathrm{kg}$ produced a full-blown withdrawal syndrome, with a median withdrawal score of 10 (maximum), and morphine $100 \mathrm{mg} / \mathrm{kg}$ followed by naloxone $2 \mathrm{mg} / \mathrm{kg}$ produced submaximal withdrawal, with a median withdrawal score of 3 . The former dose combination was used in the first series of experiments to evaluate the ability of the drug to inhibit withdrawal, whereas the latter lower dose combination was utilized in the second series of experiments to evaluate the ability of naloxone to facilitate withdrawal.

The results of the first series of experiments show that calcium channel blockers suppress the expression of naloxoneinduced withdrawal in mice rendered acutely dependent on morphine. Verapamil $20 \mathrm{mg} / \mathrm{kg}$ and diltiazem $30 \mathrm{mg} / \mathrm{kg}$ significantly inhibited morphine withdrawal. Nifedipine also inhibited the withdrawal signs, but not in a statistically significant manner. Baeyens et al reported that in morphinedependent rats, intraperitoneal administration of verapamil and flunarizine prevented diarrhea and weight loss, but not jumping observed during withdrawal. ${ }^{15}$ In our study, verapamil $20 \mathrm{mg} / \mathrm{kg}$ not only suppressed diarrhea and urination, but also reduced the incidence of stereotypical jumping. Jumping in the treated group was reduced to just $10 \%$ as compared with $80 \%$ in the control group $(P<0.05)$. Baeyens also reported that verapamil $40 \mathrm{mg} / \mathrm{kg}$ reduced the incidence of ptosis in chronic dependence studies. ${ }^{15}$ Recently, verapamil has also been found to be clinically effective in controlling opioid abstinence syndrome and more effective than chlorpromazine for this purpose. ${ }^{16}$

In the present study, diltiazem at a dose of $30 \mathrm{mg} / \mathrm{kg}$ significantly $(P<0.05)$ inhibited all the signs of naloxoneprecipitated withdrawal syndrome. Earlier studies demonstrated similar effects with diltiazem. ${ }^{17-20}$ In one study it was shown that the d-cis isomer of diltiazem is more potent than the 1-cis isomer in inhibiting naloxone-precipitated withdrawal in morphine-dependent mice in vivo and in morphinedependent rat ileum in vitro. ${ }^{21}$ In another study, the calcium channel agonist, Bay K8644, increased withdrawal signs, ie, forepaw tremors and weight loss, while the calcium channel antagonists, verapamil, diltiazem, and nicardipine, decreased forepaw tremors, weight loss, and jumping in mice acutely dependent on morphine. ${ }^{22}$

The calcium channel blockers of the dihydropyridine group, such as nifedipine, ${ }^{23}$ nitrendipine, ${ }^{24}$ and nimodipine, ${ }^{25}$ have also been reported to inhibit naloxone-precipitated withdrawal symptoms in morphine-dependent rats. However, in the present study, although nifedipine inhibited the signs of naloxone-precipitated withdrawal, this action was not statistically significant. The difference is possibly due to use of a different model and methodology. An earlier study conducted in rats did not use naloxone for withdrawal, and observed different withdrawal symptoms, including writhing, squealing, diarrhea, teeth chattering, eyelid ptosis, and wet-dog-type shaking 18 hours after terminating morphine administration. ${ }^{23}$

One study has reported that both central and peripheral mechanisms are important in the inhibition of morphine abstinence syndrome by calcium channel blockers. ${ }^{15}$ These effects are produced by an action independent of opioid receptors, because neither agent replaced naloxone from its binding sites. ${ }^{25}$ Blockade of L-type voltage-dependent calcium channels by calcium channel blockers is responsible for the attenuation of morphine withdrawal. ${ }^{26} \mathrm{~T}$-type voltagedependent calcium channels have also been shown to play a critical role in the development of morphine dependence and withdrawal. ${ }^{27}$ In addition, other agents that modify calcium flux, such as lanthanum and copper, when injected intracerebroventricularly, reduce the signs of abstinence. ${ }^{8,28}$ Calcium channel blockers have also been found to attenuate mecamylamine-precipitated nicotine withdrawal syndrome in rats. ${ }^{29}$ It appears that similar calcium-dependent mechanisms are involved in morphine- and nicotine-induced antinociception and development of tolerance and dependence. ${ }^{30}$

In the second series of experiments, the levodopa-carbidopa combination, which is known to increase catecholamines in the central nervous system, ${ }^{31}$ facilitated naloxone-induced morphine withdrawal, and the facilitation was found to be blocked by the selective alpha-1 blocker, terazosin. It is established that activation of alpha-1 adrenoceptors activate phospholipase-C, resulting in increased cytosolic calcium, ${ }^{32}$ whereas an alpha-1 blocker would prevent these steps, thereby blocking the facilitation. This provides evidence for the involvement of calcium in opiate dependence and opiate withdrawal syndrome. In one study it was shown that catecholamines (dopamine and noradrenaline) in the hypothalamus are altered by morphine use, and that the altered levels 
could be modified by a calcium channel agonist (Bay K 8644) and the calcium channel antagonists, verapamil and nimodipine. ${ }^{33,34}$ Recently, another study has found that $\mathrm{Ca}^{2+} /$ calmodulin-dependent protein kinase II is a key factor in promoting opioid tolerance and dependence. Identifying such a direct mechanism may be useful for designing pharmacological treatments for these conditions. ${ }^{35}$

\section{Conclusion}

The results of this study indicate that calcium plays an important role in the genesis of morphine dependence and withdrawal, and suggests that calcium channel blockers could be useful in the management of opioid withdrawal, and clinical trials are needed to confirm their efficacy for this purpose.

\section{Acknowledgments}

The authors wish to thank JN Sinha, former Professor of Pharmacology at King George's Medical College, Lucknow, India, for guiding this research.

\section{Disclosure}

The authors report no conflicts of interest in this work.

\section{References}

1. Emmett-Oglesby MW, Mathis DA, Moon RT, Lal H. Animal models of drug withdrawal symptoms. Psychopharmacology. 1990;101: 292-309.

2. Meehan WJ, Adelman SA. Opioid abuse. Available at: http://emedicine. medscape.com/article/287790-overview. Accessed September 21, 2010.

3. Tomkins DM, Sellers EM. Addiction and the brain: The role of neurotransmitters in the cause and treatment of drug dependence. Can Med Assoc J. 2001;164:817-821.

4. Williams JT, Christie MJ, Manzoni O. Cellular and synaptic adaptations mediating opioid dependence. Physiol Rev. 2001;81:299-343.

5. Little HJ. The role of calcium channels in drug dependence. Drug Alcohol Depend. 1995;38:173-194.

6. Pucilowski O. Psychopharmacological properties of calcium channel inhibitors. Psychopharmacology. 1992;109:12-29.

7. Harris RA, Yamamoto H, Loh HH, Way EL. Discrete changes in brain calcium with morphine analgesia, tolerance, dependence and abstinence. Life Sci. 1977;20:501-506.

8. Bhargava HN. The effects of divalent ions on morphine analgesia and abstinence syndrome in morphine tolerant and dependent mice. Psychopharmacology. 1978;57:223-225.

9. Ramkumar V, El- Fakahany EE. Increase in 3H-nitrendipine binding sites in the brain in morphine tolerant mice. Eur J Pharmacol. 1984;102: 371-372.

10. Harris RA, Loh HH, Way EL. Antinociceptive effects of lanthanum and cerium in non tolerant and morphine tolerant dependent mice. J Pharmacol Exp Ther. 1976;196:288-297.

11. Yamamoto H, Harris RA, Loh HH, Way EL. Effects of acute and chronic morphine treatments on calcium localization and binding in brain. J Pharmacol Exp Ther. 1978;205:255-264.
12. Yano I, Takemori AE. Inhibition by naloxone of tolerance and dependence in mice treated acutely and chronically with morphine. Res Commun Chem Pathol Pharmacol. 1977;16:721-734.

13. Abdelhamid EE, Sultana M, Portoghese PS, Takemori AE. Selective blockade of $\sigma$ opioid receptors prevents the development of morphine tolerance and dependence in mice. J Pharmacol Exp Ther. 1991;258: 299-303.

14. Siegel S, Castellan NJ. Nonparametric Statistics for the Behavioral Sciences. New York, NY: McGraw-Hill; 1988.

15. Baeyens JM, Esposito E, Ossowska G, Samanin R. Effects of peripheral and central administration of calcium channel blockers on the naloxone precipitated abstinence syndrome in morphine dependent rats. Eur $J$ Pharmacol. 1987;137:9-13.

16. Ansari MA, Memon Z, Ahmed SP, Ali M. Comparison of the efficacy and safety of chlorpromazine with verapamil for the treatment of acute opioid abstinence syndrome. Pak J Med Sci. 2009;25:641-645.

17. Kishioka S, Inoue N, Nishida S, Fukunaga Y, Yamamoto H. Diltiazem inhibits naloxone-precipitated and spontaneous morphine withdrawal in rats. Eur J Pharmacol. 1996;316:7-14.

18. Colado MI, Alfaro MJ, Lopez F, Del Val V, Martin MI. Effect of nimodipine, diltiazem and BAY K 8644 on the behavioural and neurochemical changes associated with naloxone-precipitated withdrawal in the rat. A comparison with clonidine. Gen Pharmacol. 1993;24: $35-41$.

19. Tokuyama S, Ho IK. Effects of diltiazem, a $\mathrm{Ca}^{2+}$ channel blocker, on naloxone-precipitated changes in dopamine and its metabolites in the brains of opioid-dependent rats. Psychopharmacology. 1996;125: $135-140$.

20. Tokuyama S, Ho IK. Inhibitory effects of diltiazem, an L-type $\mathrm{Ca}^{2+}$ channel blocker, on naloxone-increased glutamate levels in the locus coeruleus of opioid-dependent rats. Brain Res. 1996;722:212-216.

21. Caro G, Barrios M, Baeyens JM. Dose dependent and stereoselective antagonism by diltiazem of naloxone precipitated morphine abstinence after acute morphine-dependance in in vivo and in vitro. Life Sci. 1988; 43:1523-1527.

22. Barrios M, Baeyens JM. Differential effects of L type calcium channel blockers and stimulants on naloxone precipitated withdrawal in mice actually dependent on morphine. Psychopharmacology. 1991;104: 397-403.

23. Vitcheva V, Mitcheva M. Effects of nifedipine on behavioral and biochemical parameters in rats after multiple morphine administration. Methods Find Exp Clin Pharmacol. 2004;26:631-634.

24. Rabbani M, Dehkordi AJ, Ahmadi A. Acute and chronic effects of nitrendipine on naloxone precipitated morphine withdrawal in mice. Iran J Pharm Res. 2004;2:109-114.

25. Bongianni F, Carla V, Moroni F, Pellegrini, Giampietro DE. Calcium channel inhibitors suppress the morphine withdrawal syndrome in rats. Br J Pharmacol. 1986;88:561-567.

26. Mahani SE, Fathi Y, Motamedi F, Hosseinpanah F, Ahmadiani A. L-type calcium channel blockade attenuates morphine withdrawal: In vivo interaction between L-type calcium channels and corticosterone. Horm Behav. 2008;53:351-357.

27. Dogrul A, Zaglı U, Tulunay FC. The role of T-type calcium channels in morphine analgesia, development of antinociceptive tolerance and dependence to morphine, and morphine abstinence syndrome. Life Sci. 2002;71:725-734.

28. Harris RA, Loh HH, Way EL. Effect of divalent ions, cation chelators and ionophores on morphine analgesia and tolerance. J Pharmacol Exp Ther. 1975;195:488-498.

29. Biala G, Weglinska B. Blockade of the expression of mecamylamineprecipitated nicotine withdrawal by calcium channel antagonists. Pharmacol Res. 2005;51:483-488.

30. Biala G, Weglinska B. On the mechanism of cross-tolerance between morphine- and nicotine-induced antinociception: Involvement of calcium channels. Prog Neuropsychopharmacol Biol Psychiatry. 2006; $30: 15-21$. 
31. Standaert DG, Young AB. Treatment of central nervous system degenerative disorders. In: Brunton LL, Lazo JS, Parker KL, editors. Goodman \& Gilman's The Pharmacological Basis of Therapeutics. 11th ed. New York: McGraw Hill; 2006:533-543.

32. Harvey RA, Champe PC, Finkel R, Cubeddu LX, Clark M, editors. Lippincott's Illustrated Reviews in Pharmacology. 4th ed. New York: Lippincott Williams \& Wilkins; 2009:68-69.

33. Martinez-Piñero MG, Milanés MV, Vargas ML. Modulation by catecholamine of hypothalamic-pituitary-adrenocortical (HPA) axis activity in morphine-tolerance and withdrawal. Gen Pharmacol. 1994;25: 187-192.
34. Martinez-Piñero MG, Vargas ML, Milanés MV. L-type $\mathrm{Ca}^{2+}$ channel ligands modulate morphine effects on the hypothalamus-pituitaryadrenocortical axis in rats. Eur J Pharmacol. 1993;232:191-198.

35. Tang L, Shukla PK, Wang LX, Wang ZJ. Reversal of morphine antinociceptive tolerance and dependence by the acute supraspinal inhibition of $\mathrm{Ca}^{2+} /$ calmodulin-dependent protein kinase II. $J$ Pharmacol Exp Ther. 2006;317:901-909.

\section{Publish your work in this journal}

The Journal of Experimental Pharmacology is an international, peerreviewed, open access journal publishing original research, reports, reviews and commentaries on all areas of laboratory and experimental pharmacology. The manuscript management system is completely online and includes a very quick and fair peer-review system.
Visit http://www.dovepress.com/testimonials.php to read real quotes from published authors. 